\title{
A presença da OCDE no Brasil no contexto da avaliação educacional
}

\section{OECD's presence in Brazil in context of educational assessment}

\author{
Armando Daros Jr.1
}

\section{Resumo:}

Resultado de uma pesquisa sobre as relações entre Brasil e OCDE mediados pelos programas PISA e TALIS, este artigo tem como objetivo acrescentar elementos à discussão sobre a crescente utilização de instrumentos avaliativos importados como parâmetros de qualidade da educação brasileira. A partir da contextualização histórica de surgimento e da complexidade das relações internacionais, a OCDE solidificou-se como organização condutora da reconstrução europeia no pós II Guerra Mundial e articuladora das relações centroperiferia do capitalismo mundial tendo como princípio norteador o fomento ao desenvolvimento econômico associado à flexibilização das barreiras comerciais e estabilização social cristalizada a partir da melhoria da educação evidenciada pelos resultados dos testes implementados. A partir de uma análise documental com base no referencial bibliográfico elencado, os resultados indicam um alinhamento dos programas avaliativos aos interesses da atual configuração do modo de produção capitalista visto que a melhoria dos índices brasileiros coloca o país no rol dos países economicamente atrativos aos investimentos futuros.

Palavras-chave: OCDE, PISA, TALIS, Avaliação Educacional.

\begin{abstract}
:
Results of a survey on relations between Brazil and OECD mediated programs PISA and TALIS, this article aims to add elements to the discussion on the growing use of evaluative tools imported as quality parameters of Brazilian education. From the historical context of emergence and complexity of international relations, the OECD has solidified itself as an organization conducting reconstruction in Europe after World War II and articulator of center-periphery relations of global capitalism as a guiding principle and fostering economic development associated the easing of trade barriers and social stabilization crystallized from better education evidenced by the results of the tests implemented. From an analysis of documents based on bibliographic reference part listed, the results indicate an alignment of the interests of evaluative programs current configuration of capitalist mode of production since the improvement of Brazilian indices put the country on the list of countries economically attractive to future investment.
\end{abstract}

Keywords: OECD, PISA, TALIS, Educational Evaluation. 


\section{Introdução}

Este artigo tem como objetivo suscitar a discussão sobre relação entre Brasil e a Organização para a Cooperação e Desenvolvimento Econômico (OCDE) com base na descrição dos programas por este último elaborados e em vigência na educação básica brasileira, o Programa Internacional de Avaliação de Estudantes (PISA) e a Pesquisa Internacional sobre Ensino e Aprendizagem (TALIS) tomando como recorte temporal o ano de 2000, quando o Brasil participou pela primeira vez do PISA.

O fio condutor da pesquisa é a existência de um interesse comum em fortalecer a implantação no Brasil de programas avaliativos educacionais tendo em vista o respaldo internacional da OCDE cujo princípio fundante é a vinculação do desenvolvimento econômico à estabilidade social sendo um dos referenciais de destaque nesse intento as estatísticas educacionais.

Para atender ao proposto neste artigo, o texto foi organizado da seguinte forma: na primeira etapa fez-se um levantamento do surgimento da OCDE no contexto da reconstrução da Europa. Na etapa posterior, descrevemse os projetos vinculados à OCDE para educação brasileira em vigência. Na etapa de conclusiva, procurou-se demarcar alguns questionamentos com relação ao interesse da OCDE na educação brasileira. O trabalho de caráter teórico foi elaborado utilizando-se de pesquisa das fontes primárias, mais precisamente os documentos gerados pela OCDE e pelos seus parceiros locais, os quais descrevem as ações implementadas no país no campo da educação, bem como fontes secundárias citadas no decorrer do texto.

\section{O surgimento da OCDE: reconstrução, desenvolvimento e estabilidade da Europa}

Interesses comerciais entre países economicamente díspares, conflitos fronteiriços, étnicos, políticos, impasses cuja solução amiúde resultaram em guerras com elevados custos materiais e humanos sem que houvesse como contrapartida resultados positivos propiciaram a consolidação das denominadas Organizações Intergovernamentais Internacionais (HERZ e HOFFMAN, 2004) como mecanismo de estabilização do sistema de relações internacionais. Essas organizações podem variar bastante em tamanho e funções, podendo conter apenas três membros ou a maioria dos países livres, atender a uma demanda específica ou de caráter geral, mas certamente presente no processo de governança mundial. Outra característica dessas organizações é a elaboração de mecanismos de estabilização dentre eles, balanço e poder, zonas de influência, direito internacional e estabilidade hegemônica.

Não por acaso o fim da Segunda Guerra Mundial (1939-1945) é um marco na consolidação da OCDE criada a partir da política de estabilidade hegemônica² norte americana após a Segunda Guerra Mundial.

Ao término dos conflitos da Segunda Grande Guerra (1939-1945) os Estados Unidos despontaram como a maior potência econômica e militar mundial. Seus esforços em suprir as necessidades do campo de guerra na Europa levaram suas indústrias a um aumento da produção bélica de 2\% em 1939 do produto total para 40\% em 1943. Contudo, a produção de materiais não bélicos também aumentou significativamente, pois a indústria norte americana não tinha sido destruída tal qual ocorrera com a europeia. Não surpreende que a expansão industrial americana tenha crescido num valor de mais de $15 \%$ ao ano no período de 1940 a 1944 e que não mais tenha atingido tamanho crescimento (KENNEDY, 1989).

O setor privado de exportação, no entanto, demonstrou preocupação de que este cenário de produção crescente fosse seriamente afetado por uma depressão pós-guerra nos países europeus e pelo declínio dos gastos governamentais norte americanos. A estratégia de defesa do livre comércio, entre americanos e europeus resultou na elaboração de uma série de acordos como o Acordo Geral de Tarifas e Comércio (GATT) e de organismos como o Fundo Monetário Internacional (FMI), Banco Internacional de Reconstrução

2 Estabilidade hegemônica é a atuação de uma grande potência que garante o surgimento de instituições internacionais (HERZ e HOFFMAN, 2004). 
e Desenvolvimento (BIRD) entre 1942 e 1946, promovendo o estabelecimento de uma nova ordem mundial benéfica às necessidades do capitalismo ocidental, garantindo o soerguimento das economias europeias e, é claro, o domínio do mais florescente dos Estados ocidentais engajando o Velho Continente ao estabelecido pelos Estados Unidos:

Os países que desejavam obter alguns dos recursos disponíveis para a reconstrução e desenvolvimento sob esse novo regime econômico viram-se obrigados a aceitar as exigências americanas de livre conversibilidade das moedas e da livre concorrência - ou afastar-se totalmente do sistema (como fizeram os russos, quando perceberam sua incompatibilidade com os controles socialistas) (KENNEDY, 1989, p.345).

Entretanto, não se poderia esperar um equilíbrio nas transações, já que se tratava de parceiros econômicos devastados por seis anos de guerra. Um sistema de laissez faire nessas condições obviamente beneficiaria o lado mais forte.

Diante da necessidade de recuperar os países parceiros para padrões econômicos mais estáveis e afastar a influência da União Soviética, ao menos na parte ocidental do continente europeu, os Estados Unidos criaram um plano de recuperação econômica conhecido como Plano Marshall: "uma injeção no braço, num momento crítico" (KENNEDY, 1989, p.402). Essa injeção providencial resultou numa recuperação da economia em ritmo acelerado devido ao comércio cada vez mais intenso e livre de barreiras com os Estados Unidos: "Na Alemanha Ocidental, a renda per capita cresceu de 320 dólares em 1949 para 9.131 dólares em 1978, na Itália passou de 638 dólares em 1960 para 5.142 em 1970" (KENNEDY, 1989, p. 402).

A fim de dar seguimento ao montante ofertado pelos Estados Unidos, dezesseis países ${ }^{3}$ reuniram-se em 1947 em Paris para criar a Organização Europeia de Cooperação Econômica (OECE) a fim de estabelecer práticas para uma estreita cooperação nas suas relações econômicas com objetivo de recuperar o desenvolvimento econômico, aumentar seu comércio, diminuir os entraves e manter a estabilidade nas economias dos países signatários (CAMPOS, 2010, p. 450).

Diante das novas condições econômicas e estabelecidas relações de poder que polarizam o mundo em torno de dois blocos opostos, capitalista e comunista, reconfigura-se o conceito de interdependência resultando na ampliação dos limites geográficos de atuação dessa organização.

Atualmente a OCDE é estruturada de forma a atuar sobre as mais variadas áreas como economia, ciência, comércio, emprego, mercado financeiro e educação através do levantamento de dados, análise, discussão e orientação aos países na forma de publicações compostas das estatísticas e resultados das pesquisas e recomendações. Para tanto são firmados acordos de cooperação e intercâmbio com países não membros, mais de 100, no que tange a projetos de desenvolvimento e estabilização econômica.

Sendo um dos pontos chave para o desenvolvimento econômico, a educação está vinculada à Direção para a Educação ${ }^{4}$, responsável por atividades que focalizam a elaboração e análise de pesquisas educacionais, cujos resultados formam uma base de dados utilizada para a elaboração das orientações da organização à implementação das políticas educacionais dos países envolvidos. Dentre as atividades da Direção para a Educação, os instrumentos de avaliação de desempenho de estudantes, no caso o PISA, é destacado mundialmente, sendo utilizado por 63 países. Com base no resultado de suas pesquisas, a OCDE publica materiais relacionados às várias etapas da educação como documentos orientadores de políticas educacionais dos países membros e não membros. A fim de divulgar seus resultados e firmar suas propostas, a OCDE promove reuniões internacionais nos quais os exemplos exitosos são postos em destaque através de dados comparativos e análises sobre a educação que auxiliam na decisão política sobre projetos e programas que colaboram na melhoria nos resultados da aprendizagem (OCDE, 2012a).

3 Áustria, Bélgica, Dinamarca, França, Grécia, Irlanda, Islândia, Itália, Luxemburgo, Noruega, Holanda, Portugal, Reino Unido, Suécia, Suíça e Turquia.

4 Este órgão está subdividido em cinco departamentos: Children and Schools (ECS), Skills Beyond School (SBS), Innovation and Measuring Progress (IMEP), Policy Advice and Implementation (PAI), Programme for Co-operation with Non-member Economies (NME). 
Na visão da OCDE, a educação possui um papel central como resposta às demandas da reestruturação do capitalismo emergente, sobretudo, a partir do neoliberalismo nos anos 1980-1990, mas também aos impactos sociais dela recorrentes. Propõe-se, portanto, a enfatizar a necessidade da preparação do indivíduo a uma economia que requer uma formação profissional habilitada para os desafios, inclusive da flexibilidade do emprego. Elementos como inovação, preparação para as rápidas transformações do mercado de trabalho, investimento no capital social e humano fazem parte do discurso do desenvolvimento econômico com equilíbrio social:

Na área da educação, o lugar mais importante para os países ricos é a OCDE. 0 thinking tank, como dizem os norte-americanos, isto é 0 reservatório para ideias. Saíram da OCDE a "reforma da matemática moderna", a ideia e a primária expressão de "qualidade da educação", a ideia de "economia do saber", a de "formação ao longo de toda a vida". A OCDE é o centro do pensamento neoliberal no que tange à educação. Não é de admirar-se disso quando se sabe que foi explicitamente criada para promover a economia de mercado (CHARLOT, 2007, p.133).

\section{Brasil e OCDE: envolvimento ampliado através da educação}

O Brasil não integra a OCDE, porém faz parte de uma estratégia por ela denominada envolvimento ampliado (enhanced engagement), que estabelece um vínculo com países emergentes, nesse caso Rússia, Índia, China, África do Sul, Indonésia e Brasil, que ainda não passaram pelo protocolo de associação já que "O processo de adesão é complexo e pode ser demorado, pois envolve uma série de exames que visam avaliar a capacidade de um país para cumprir as normas da OCDE em muitas áreas. Isso torna difícil para acolher novos membros ao mesmo tempo" (OCDE, 2012b). Mesmo assim, a Organização elabora levantamento e análise de dados nos mais diversos aspectos econômicos e sociais desses países.

Um dos resultados do envolvimento ampliado foi a inclusão do Brasil em 2003 no Ponto de Contato Nacional, órgão composto por diversos ministérios e coordenado pela Secretaria de Assuntos Internacionais do Ministério da Fazenda, tendo como objetivo fomentar o seguimento das Diretrizes da OCDE para as Empresas Multinacionais, as quais buscam harmonizar as relações entre governo local e multinacionais, bem como destas com a sociedade:

0 objetivo comum dos governos que aderiram às Diretrizes é encorajar as contribuições positivas que as empresas multinacionais podem dar ao progresso econômico, ambiental e social e minimizar os problemas que possam ser gerados pelas respectivas atividades. Na busca deste objetivo, os governos agem em parceria com as muitas empresas, sindicatos e organizações não governamentais cujas atividades visam ao mesmo fim. A contribuição dos governos passa pela criação de quadros regulatórios internos eficazes e que incluam políticas macroeconômicas estáveis, tratamento não discriminatório das empresas, regulação adequada e supervisão prudencial, um sistema imparcial de administração da justiça e aplicação da lei e uma administração pública honesta (BRASIL, 2012).

Um dos acordos de maior destaque entre Brasil e OCDE no campo educacional está na avaliação de desempenho em larga escala. Desde 2000, o Brasil participa do PISA. A instituição responsável pela implementação do PISA no Brasil é o Instituto Nacional de Estudos e Pesquisas Educacionais Anísio Teixeira - INEP, autarquia do Ministério da Educação, responsável também pela organização e manutenção do sistema de informações e estatísticas educacionais, bem como pelo desenvolvimento de programas de avaliação educacional.

O PISA é um programa de avaliação trienal do qual participam alunos da educação básica em determinadas áreas do conhecimento, sendo que um das áreas é priorizada alternadamente. O PISA tem como principal objetivo produzir, em todos os países envolvidos, indicadores de desempenho estudantil voltados para as políticas educacionais, fornecendo orientações, incentivos e instrumentos para melhorar a efetividade da educação, além de possibilitar a comparação internacional (INEP, 2012a). Em 2000, foram avaliados alunos de 15 anos de idade nas áreas de Matemática, Ciências e Leitura, com prioridade na área de Leitura. Nas aplicações subsequentes, foram avaliados com especial ênfase os domínios de Matemática (2003); Ciências (2006) e Leitura (2009). Em 2012, a ênfase foi em Matemática. Os itens de cada aplicação principal do PISA são analisados por todos os países participantes do programa e pré-testados com um ano de antecedência. O Brasil participou das seguintes Avaliações: Leitura; Matemática; Ciências; Resolução de Problemas; Leitura Eletrônica e Matemática Eletrônica. A aplicação do PISA 2012 foi realizada em uma amostra representativa de 
escolas brasileiras que possuíam estudantes nascidos em 1996 e matriculados nos três últimos anos do ensino fundamental ou em qualquer série do ensino médio (denominados "estudantes elegíveis"). Com relação à estimativa de custos, o projeto básico do PISA-2012 está estimado em $R$ \$2.869.105,37 segundo o INEP (2012a). De acordo com o documento Projeto Básico PISA 2012, as avaliações buscaram ultrapassar os resultados que indicam apenas um determinado nível de aquisição de conteúdos disciplinares deslocados de sua relação com o uso social destes, portanto, defende a ideia que o estudante tenha capacidade de fazer as inferências que o texto exige e relacioná-lo a outras áreas do conhecimento, reforçando o conceito da interdisciplinaridade enfatizado desde seus primeiros documentos direcionados à educação (JANTSCH e BIANCHETTI, 1995). A característica da avaliação do PISA é utilizar-se da concepção de letramento que na sua ótica

pretende refletir a amplitude dos conhecimentos e competências que estão sendo avaliados. 0 PISA procura ir além do conhecimento escolar, examinando a capacidade dos alunos de analisar, raciocinar e refletir ativamente sobre seus conhecimentos e experiências, enfocando competências que serão relevantes para suas vidas futuras, na solução de problemas do dia a dia (INEP, 2012C).

A concepção de letramento trazida pela OCDE aponta para a dimensão social em detrimento da sua dimensão individual, isto é, enfatiza os elementos mais significativos no estabelecimento das relações sociais ao contrário da mera aquisição de habilidades individuais, enfatizando que há

duas principais dimensões do letramento: a dimensão individual e a dimensão social. Quando o foco é posto na dimensão individual, 0 letramento é visto como um atributo pessoal, parecendo referir-se, como afirma Wagner (1983, p. 5), à 'simples posse individual das tecnologias mentais complementares de ler e escrever'. Quando o foco se desloca para a dimensão social, o letramento é visto como um fenômeno cultural, um conjunto de atividades sociais que envolvem a língua escrita, e de exigências sociais de uso da língua escrita. Na maioria das definiç̧̃̃es atuais de letramento, uma ou outra dessas duas dimensões é priorizada: põe-se ênfase ou nas habilidades individuais de ler e escrever, ou nos usos, funções e propósitos da língua escrita no contexto social. (SOARES apud BONAMINO, COCARELLI e FRANCO, 2010, p. 99).

Se por um lado o programa demonstra uma preocupação com a dimensão social do letramento, que na versão da OCDE é a aquisição de habilidades educativas adequadas às exigências do mercado de trabalho, de outro desconsidera as particularidades da composição social das populações avaliadas recaindo num antigo vício dos projetos educacionais anteriormente importados pelo Brasil: fórmulas universais para questões locais:

A economia diversificada do Brasil ainda é fortemente baseada em commodities e, sendo assim, ainda depende de mão de obra não qualificada em muitos setores. Todavia, no futuro, a economia vai cada vez mais depender de quanto sua força de trabalho possa adicionar valor às matérias-primas que produz. 0 Brasil sabe que precisa produzir um número de trabalhadores qualificados muito maior do que o que está produzindo no momento. É esse fato que está conduzindo à demanda tanto por uma quantidade maior de trabalhadores escolarizados como por melhorias na qualidade da educação (OCDE, 2011b, p.194).

A OCDE interessa-se não só pelo desempenho dos alunos, mas também pela avaliação dos professores entendendo que existe uma relação intrínseca entre rendimento escolar e formação docente.

Com enfoque na avaliação do professorado, o Brasil implementou a TALIS, pesquisa coordenada pela OCDE em parceria com o INEP em nível nacional. Seu objetivo é o levantamento de dados sobre o ambiente de aprendizagem e as condições de trabalho oferecidas ao professor pela escola. Fazem parte da pesquisa os professores das séries finais do ensino fundamental ( $6^{\circ}$ a $9^{\circ}$ ano ou $5^{a}$ a $8^{a}$ série) e dos diretores das escolas da amostra. Nas primeiras pesquisas realizadas, 2007 e 2008, foram coletadas informações sobre liderança escolar, avaliação dos professores e feedback, desenvolvimento profissional e atitudes, crenças e práticas educacionais. Na versão 2012, foram selecionadas 1000 escolas de todos os Estados segundo o INEP (2012b).

Face aos frequentes conflitos surgidos no decorrer das transformações no campo social, a figura do professor ganhou destaque por ser peça fundamental na melhoria do rendimento e aquisição dos alunos, portanto a OCDE coloca o investimento do poder público na formação e qualificação de professores como prioridade:

A qualidade do corpo docente é um fator de primeiro plano, quando um país, qualquer que seja, aspira a excelência de seu sistema educacional. Os professores constituem 0 centro do sistema escolar, e as pesquisas mais diversas confirmaram quanto a qualidade dos professores conta na aquisição dos alunos. É por isso que os poderes públicos levam tão a sério a melhoria da qualidade dos professores, para assegurar que todos os alunos se beneficiem de um bom ensino (OCDE apud MAUÉS, 2010, p. 77). 
Entretanto, mesmo salientando a importância do professor como fator decisivo na aquisição dos alunos, o discurso elogioso não se estende às instituições nas quais eles são formados, sobretudo quando se tratam de instituições públicas. A crítica da OCDE recai sobre a inadequação de formação obliterada pelas questões de teor ideológico, sobretudo antes das reformas implementadas no governo Fernando Henrique Cardoso:

As universidades públicas tinham as licenciaturas como cursos de segunda categoria que ficavam confinados às faculdades menos concorridas. Muito do trabalho do curso era teórico com foco ideológico que convencia os professores de que os problemas sociais, e não a qualidade docente, eram os principais responsáveis pelo fracasso dos estudantes (OCDE, 2011b, p. 182).

Embora fonte de preocupação, as pesquisas realizadas pela OCDE dão pouca ênfase à condições materiais (salário, plano de carreira, etc) dos professores. Essa é uma lógica coerente com os objetivos da Organização, já que o foco está em atender países que são atingidos pelas crises cíclicas do capitalismo e muitas vezes apresentam problemas com o orçamento comprometido com o pagamento do funcionalismo público, o que impossibilita maiores reservas para o financiamento do setor produtivo privado, sendo assim:

As medidas propostas não indicam uma preocupação real com a valorização do magistério no sentido de desenvolver ações que garantam uma formação inicial e continuada com qualidade, um plano de cargos e salários que represente um estímulo para entrar ou permanecer nesse métier e um reconhecimento social que traduza o verdadeiro papel que o professor desempenha na sociedade (MAUÉS, 2010, p. 84).

\section{Considerações Finais}

O presente artigo propôs-se a apresentar os enlaces entre Brasil e OCDE por meio de uma sucinta descrição do PISA e TALIS, programas no campo educacional voltados à avaliação, haja vista a presença crescente dessa organização no país.

Ressalvas feitas às limitações do trabalho, alguns apontamentos emergem a partir da reflexão sobre seu conteúdo.

A organização da qual a OCDE é descendente, a OECE foi criada com a finalidade de auxiliar na recuperação das economias bem como reforçar os laços comerciais e garantir e estabilidade social dos países signatários. $\mathrm{O}$ quadro conjuntural de surgimento da organização possibilita entender sua função articuladora supranacional na manutenção da ordem capitalista mundial. Surgida num momento de instabilidade social e política, concretizou a hegemonia norte americana através de investimentos que permitiram afastar o avanço do comunismo nos países europeus ocidentais mais afetados pela II Guerra Mundial. A partir das transformações ocorridas no quadro das relações econômicas mundiais e no decorrer das décadas vindouras, a OCDE ampliou seu escopo de atuação alcançando países além das fronteiras europeias.

É compreensível que entre premissas da organização, coesão e estabilidade social estejam associados ao desenvolvimento econômico: episódios como a crise do petróleo, crise da dívida externa dos países em desenvolvimento levaram a um acirramento do desequilíbrio social potencialmente danoso ao acúmulo do capital, não apenas pela dificuldade dos credores internacionais em reaver os empréstimos feitos aos países periféricos, mas também pela crescente insatisfação das camadas trabalhadoras da população desses países com a condução da economia por parte dos países capitalistas centrais. O modelo neoliberal, receituário dominante no círculo político-econômico do Consenso de Washington em 1989 como resposta à falência dos países em desenvolvimento, mostrou-se ineficaz na solução dos problemas sociais resultando na necessidade de formulação de novas estratégias fomentadas em grande parte pelo Banco Mundial no combate à pobreza extrema (FONSECA, 1999). Na busca da estabilidade social, a educação tornou-se um componente basilar pelo seu potencial de (con)formação de um indivíduo às transformações no mundo do trabalho decorrentes da reorganização do capital.

O desenvolvimento econômico via investimento no capital humano tornou-se um mote recorrente à implementação de políticas educacionais dos países assessorados pela OCDE. Pesquisas desenvolvidas em 
regiões específicas evidenciam o vínculo que a OCDE mantém entre educação e desenvolvimento econômico. Em 2011, apresentou um dossiê sobre a educação superior intitulado Higher education in regional and city development: State of Paraná, Brazil, 2011, com o apoio da Federação das Indústrias do Estado do Paraná (FIEP), tendo como finalidade não apenas descrever as instituições universitárias públicas paranaenses nos seus aspectos organizacionais, físicos e pedagógicos, mas também as potencialidades econômicas de cada região (OCDE, 2011a).

O conteúdo do relatório busca levantar as possibilidades das universidades em atender às demandas regionais de crescimento. Para divulgar os propósitos da pesquisa foram patrocinados encontros em locais estrategicamente escolhidos pela sua relação com o desenvolvimento regional. A qualidade da Educação Superior na concepção da OCDE é avaliada a partir de uma perspectiva economicista que explicita como propósito da Educação Superior a "ênfase nos aspectos de potencialização do crescimento da economia e da empregabilidade" (BERTOLIN, 2009, p.134). Segundo o documento Quality and Internationalisation in Higher Education, a qualidade de uma instituição de Educação Superior é avaliada a partir do equilíbrio entre o investimento público, os requisitos da sociedade e a eficiência dos egressos:

Com o incremento de recursos [públicos para a educação superior] vem um incremento relativo ao papel do governo em garantir três enquadramentos. Em primeiro lugar, estão as IES claramente planejadas e organizadas para produzir os graduados requeridos pela sociedade, isto é, são seus objetivos apropriados? Em segundo lugar, o dinheiro esta sendo bem gasto, isto é, estão as IES operando de forma eficiente? E, em terceiro lugar, estão as IES produzindo os egressos desejados, isto é, estão eles operando eficientemente? Essas questões têm conduzido para novas interpretações do conceito de qualidade (OCDE apud BERTOLIN, 2009, p.135).

O atual quadro econômico mundial reserva ao Brasil uma posição mais confortável. Se muitas das mazelas sociais permanecem sem solução, o setor econômico financeiro destaca-se frente a um quadro de instabilidade econômica na Europa com reflexos nos Estados Unidos, o que leva seus investidores ao encontro de mercados mais promissores.

A partir dessa lógica, o país busca firmar sua condição de economicamente atrativo ao atender aos requisitos estabelecidos internacionalmente através do aval da OCDE. Importa por conseguinte por em evidência as relações cada vez mais sólidas entre Brasil e OCDE no campo educacional tendo em vista implicações muito mais complexas que o mero apelo à justiça social por meio de acesso escolar já que

A lógica do desenvolvimento econômico forçou a colocar em pauta essa questão. À medida que a posição econômica do Brasil progride, não é mais possível depender do trabalho barato. As companhias podem treinar trabalhadores para as funções básicas, mas sair de uma economia de commodities para outra baseada em agregar valor às matérias-primas requer mais do que uma força de trabalho bem treinada (OCDE, 2011b, p.178).

Programas de avaliação em larga escala devem ser utilizados como indicadores para uma política de melhoria da qualidade da educação e das condições de atuação docente, porém a exposição de resultados sem a devida ponderação dos fatores sociais tem levado apenas a um "ranqueamento" dos sistemas escolares, ou pior, um ranqueamento de países desiguais com realidades desiguais. Até mesmo pesquisas promovidas pelo Banco Mundial apontam esse impasse:

existem dificuldades específicas quando países em desenvolvimento estão envolvidos num estudo desenhado para países industrializados, pois os fatores socieconômicos dos primeiros podem ser muito diferentes daqueles que prevalecem nos países industrializados e podem incluir pobreza, aspectos nutricionais e de saúde, infraestrutura educacional precária e carência de financiamento (GREANEY e KELLAGHAN, 2011, p. 78).

O enunciado do qual a OCDE é caudatária da "educação e capacidades para o forte, sustentável e equilibrado crescimento no século 21" (OCDE, 2012a) quando elide as relações de poder sob a égide do capitalismo soam nesse contexto mais como uma conjectura que uma afirmação. 


\section{Referências Bibliográficas}

BONAMINO, A; COCARELLI, C.; FRANCO, C. Avaliação e letramento: concepções de aluno letrado subjacentes ao SAEB e ao PISA. Educação e Sociedade, Campinas, vol. 23, n. 81, p. 91-113, dez. 2010. Disponível em <http://www.cedes.unicamp.br>. Acesso em: 01/07/2012.

BRASIL. Ministério da Fazenda. Diretrizes da OCDE para empresas multinacionais. Disponível em: http:// www.fazenda.gov.br/sain/pcn/PCN/diretrizes.asp. Acesso em: 26/07/2012.

BERTOLIN, J. C. G. Qualidade em educação superior: da diversidade de concepções a inexorável subjetividade conceitual. Avaliação, Campinas; Sorocaba, SP, v. 14, n. 1, p.127-149, mar. 2009.

CAMPOS, J. M. de. Organizações internacionais: teoria geral. 3 ed. 2 reimp. Curitiba: Juruá, 2010.

CHARLOT, B. Educação e globalização: uma tentativa de colocar ordem no mercado. Sísifo, Revista de ciências da educação, Lisboa n. 4, out/dez 2007.

FONSECA, M. O Banco Mundial e a educação: reflexões sobre o caso brasileiro. In: GENTILI,P. (org.). Pedagogia da exclusão: crítica ao neoliberalismo em educação. 5 ed. Petrópolis, 1999. p. 169-195.

GREANEY, V.; KELLAGHAN, T. Avaliação dos níveis de desempenho educacional: pesquisas do Banco Mundial sobre avaliações de desempenho educacional. Traduzido por Maria Lucia de Oliveira. Rio de Janeiro: Elsevier, 2011.

HERZ, M.; HOFFMAN, A. R. Organizações internacionais: histórias e práticas. Rio de Janeiro: Elsevier, 2004.

INEP (Instituto Nacional de Estudos e Pesquisas Educacionais Anísio Teixeira). PISA. Disponível em: http:// talis.inep.gov.br/web/guest/pisa-programa-internacional-de-avaliacao-de-alunos.Acesso em: 21/07/ 2012a.

TALIS: Histórico e resultados. Disponível em:http://talis.inep.gov.br/historico-e-resultados. Acesso em: 21/07/ 2012b.

Projeto básico PISA 2012. http://downloads/acoes_internacionais/pisa/itens/2011/projeto_basico_ aplicacao_pisa_2012_rev2.pdf. Acesso em: 20/01/2012c.

JANTSCH, A. P.; BIANCHETTI, L.(orgs.). Interdisciplinaridade: para além da filosofia do sujeito. Petrópolis: Vozes, 1995.

KENNEDY, P. Ascensão e queda das grandes potências: transformação econômica e conflito militar de 1500 a 2000. 20 ed. Tradução de Waltensir Dutra. Rio de Janeiro: Elsevier,1989.

MAUÉS, O. C. A política para a educação e a formação docente. A nova regulação? Educação, Porto Alegre, v. 34, n. 1, p. 75-85, jan./abr. 2010.

OCDE (Organização para Cooperação e Desenvolvimento Econômico). Higher Education in Regional and City Development: State of Paraná, Brazil. Paris: OCDE, 2011a.

Capítulo 8: Brasil: lições encorajadoras de um grande sistema federal. Traduzido por INEP Instituto Nacional de Estudos e Pesquisas Educacionais Anísio Teixeira). Brasília, INEP, 2011b.

Work on education (2012-2013). Disponível em: http://oecdmybrochure.org/. Acesso em: 23/07/2012a.

Enlargement and enhanced engagement. Disponível em:http://www.oecd.org/home/0,3675, en_2649_201185_1_1_1_1_1,00.html. Acesso em: 24/07/2012b.

Recebido em Setembro de 2012 Aprovado em Maio de 2013 